\title{
Bullous lesions of the skin and mucous membranes in primary amyloidosis
}

\author{
J. M. A. NORTHOVER \\ M.B., B.S.
}

D. G. C. PRESBURY
M.B., B.S., M.R.C.P.(U.K.)
J. D. PICKARD

M.A., M.B., B.Chir.

R. HASKELL

M.B., B.S., B.D.S., M.R.C.P., F.D.S., R.C S.
I. M. MURRAy-LyoN

B.Sc., M.B., M.R.C.P.Ed.

D. A. KeITH

B.D.S., F.D.S., R.C.S.

The Liver Unit, Department of Medicine, Department of Dermatology and the Dental School, King's College Hospital, London, S.E.5

\section{Summary}

Four cases of primary amyloidosis are described in which bullous lesions of the skin or oral mucosa were a prominent clinical feature. Biopsy of such lesions and demonstration of amyloid by special staining may be of great diagnostic help.

\section{Introduction}

Many varieties of skin lesion have been described in primary systemic amyloidosis including macules, papules, nodules, plaques and subcutaneous haemorrhages, usually petechial but sometimes larger (Brownstein \& Helwig, 1970b). The association of amyloidosis with bullous lesions of the skin or oral mucosa has only rarely been reported but we have seen three patients in whom this striking manifestation was the presenting symptom and in a fourth patient bullae were a prominent feature of the clinical picture.

\section{Case reports \\ Case 1}

A female aged 71 was admitted to King's College Hospital in April 1957 with a history of a blotchy purpuric rash for the past 2 years. Examination revealed extensive purpura of the face, trunk and limbs and haemorrhagic bullae on the arms and back. She also had striking macroglossia and gross peripheral oedema. The latter was attributed to amyloid infiltration of the myocardium and the nephrotic syndrome. Skin biopsy demonstrated amyloid infiltration of the dermis deep to areas of haemorrhage. She continued to have repeated crops of haemorrhagic bullae on the trunk and limbs (Fig. 1) and her condition deteriorated gradually till her death in September 1957. Necropsy revealed amyloid infiltration of the skin, tongue, heart, liver, spleen, lung, thyroid and intestines.

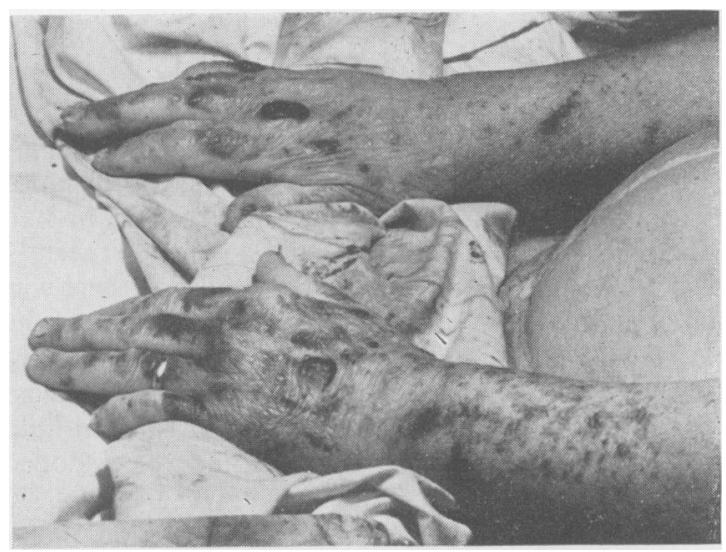

FIG. 1. Case 1. Extensive purpura of the arms with haemorrhagic bullae on the hands.

\section{Case 2}

A 52-year-old man first presented in 1965 with a 1-year history of impotence and paraesthesiae in the legs. Clinical signs of a peripheral neuropathy were present on examination, and an oral glucose tolerance test was abnormal ( $2 \mathrm{hr}$ blood glucose 310 $\mathrm{mg} / 100 \mathrm{ml}$ ). He was treated with chlorpropamide. In February 1970 the sensory deficit was more marked and he was found to have proteinuria $(2 \mathrm{~g}$ albumin/ $24 \mathrm{hr}$ ). In August 1970 he noted hesitancy of micturition and began to experience syncopal attacks, one of these leading to his admission to King's College Hospital in April 1971. The supine blood pressure then was $90 / 60 \mathrm{mmHg}$ and he was unable to stand because of postural hypotension. Other symptoms related to chronic urinary retention, rectal incontinence and an extensive sensory-motor peripheral neuropathy affecting the legs more than the arms. 
Bullae were seen on the hands and feet and he had had crops of lesions over the preceding few months.

At this time an oral glucose tolerance test was normal. The serum albumin was only $2 \cdot 1 \mathrm{~g} / 100 \mathrm{ml}$ and the urine contained 4-8 $\mathrm{g}$ albumin $/ 24 \mathrm{hr}$. Renal biopsy showed infiltration of glomeruli by amyloid and jejunal biopsy and prostatic tissue removed at transurethral resection were also involved. Synacthen test was normal. His disabling postural hypotension was not helped by ephedrine, amphetamine or $9 \alpha$ fluorohydrocortisone. Indeed the latter drug produced severe fluid retention and his condition gradually deteriorated and he died with a terminal Klebsiella pneumonia.

Necropsy confirmed amyloid infiltration of kidney, spleen, pancreas, prostate, heart, lung, bladder, sympathetic ganglia and peripheral nerves. Amyloid was present in the dermis particularly deep to the bullae and also around blood vessels, nerves and adnexae.

\section{Case 3}

A 51-year-old man was admitted to King's College Hospital with a 1-year history of crops of 'blood-blisters' on his tongue. For 6 months he had complained of postural dizziness and more recently impotence and dysphagia. On examination there was a bulla $8 \mathrm{~mm}$ in diameter on the under surface of the tongue (Fig. 2). Blood pressure was $95 / 60 \mathrm{mmHg}$ supine and $75 / 60 \mathrm{mmHg}$ erect. There was gross hepatomegaly. Bullae containing blood-stained fluid and petechial haemorrhages subsequently developed repeatedly in the buccal mucosa.

Investigations indicated widespread amyloid deposition with involvement of liver confirmed by biopsy, heart with first degree heart block on the ECG, oesophagus with poor motility shown by barium swallow, and the kidney accompanied by gross proteinuria. Biopsy of the bullous lesions of the

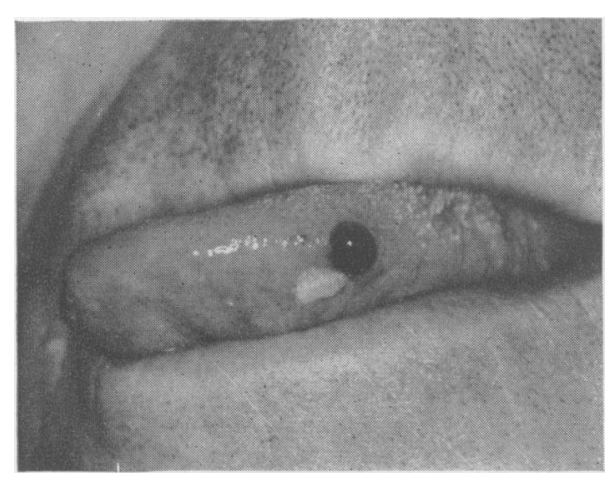

Fig. 2. Case 4. Haemorrhagic bulla on the margin of the tongue. tongue and buccal mucosa revealed subepithelial bullae with extensive amyloid deposition in the underlying tissues.

The patient died suddenly and necropsy revealed amyloid infiltration of the liver, spleen, kidneys, heart, larynx, gut and peripheral nerves.

\section{Case 4}

A 55-year-old woman first complained of crops of $\stackrel{\nabla}{\unrhd}$ 'blood-blisters' on the tongue and palate in August \& 1970 and at that time hepatomegaly was noted. A diagnosis of amyloidosis was made in July 1971 when she had an episode of melaena. The liver was now much larger and splenomegaly was also present. Liver biopsy revealed extensive amyloid infiltration but there was no evidence of involvement of other organs and the gastrointestinal bleeding was attributed to a duodenal ulcer which was noted on barium meal.

\section{Discussion}

Amyloidosis may be confined to the skin when it usually occurs as lichen amyloidosis, its macular variant, or the tumifactive type (Brownstein \& Helwig, 1970a), but many other patterns of cutaneous involvement may occur as part of systemic primar amyloidosis (Brownstein \& Helwig, 1970b). Bullou\& N skin lesions have been described in the latter condes. tion (Goltz, 1952; Chow \& Burns, 1967; Mulle Sams \& Dobson, 1969) but seem to be the least common cutaneous manifestation. The bullae develop as a result of shearing in intradermal amyloid deposits, are therefore subepidermal in position as shown in the first three cases, and often contain blood. As in our second case Muller et al. (1969) were able to produce bullae by rubbing apparently normal skin with gauze.

Bullae within the mouth are more common and have been described by several authors (Lubarsch, 1929; Moschcowitz, 1936; Baber, 1947; Reimann, Sahyoun \& Chaglassian, 1954; Ware \& Silverman, 1961). They are found typically on the tongue, the buccal or labial mucosa and are usually associated with petechial haemorrhages. There should be no confusion with congenital or hereditary epidermolysis bullosa which may, however, rarely be complicated by the development of secondary amyloidosis (Muller et al., 1969). Clinically detectable skin involvement with amyloid is extremely rare in the secondary form of the disease although deposits may be seen in the vessels and adnexae on histological examination of clinically normal skin (Brownstein \& Helwig, 1970b).

Other cutaneous manifestations of primary systemic amyloidosis include purpura and ecchymoses of the face, neck and extremities as in our first case and as the intradermal bleeding is readily induced by 
mild trauma this has been suggested as an aid to diagnosis (Hurley \& Weinberg, 1964). Skin deposits of amyloid may also produce yellowish papules, nodules or plaques but these may sometimes be darker due to intralesional bleeding. Similar deposits may also be seen in all parts of the oral mucosa and biopsy of the lesion will readily confirm the diagnosis. However, in suspected cases where there are no such lesions biopsy of the apparently normal tongue or mucobuccal fold may provide histological confirmation of amyloidosis. This is preferable to gingival biopsy (Lehner, 1968). Macroglossia, probably the best known oral manifestation of primary amyloidosis, occurs in about $45 \%$ of cases (Rukavina et al., 1956), and tongue biopsy is diagnostic. Patients may sometimes complain of xerostomia due to amyloid infiltration of salivary tissue and if it is associated with lacrimal gland involvement this may lead to a diagnosis of the sicca syndrome (Golz, 1952).

Two of our cases had autonomic neuropathy and in one the postural hypotension was incapacitating. Neurological involvement occurred in $14 \%$ of 154 cases of primary amyloidosis reported by Rukavina et al. (1956) and orthostatic hypotension was noted in $8 \%$ of 138 cases by Kyle, Rottke \& Schirger (1966). It seems that the autonomic ganglia and peripheral nerves are predominantly affected.

The diagnosis of systemic amyloidosis is often difficult and may be delayed for many months but wider recognition that bullous lesions containing amyloid may occur in the mouth and skin should facilitate diagnosis in some cases.

\section{Acknowledgments}

We thank Dr D. I. Williams for persmission to report the first case and to Dr I. V. Wilson and Professor A. Polak for referring cases 3 and 4 . We are most grateful to Dr R. H.
Marten for his help and to Dr Roger Williams for his permission to report these cases and for his help and advice in preparing this paper.

\section{References}

BABER, M.D. (1947) Amyloid macroglossia. Lancet, i, 210

Brownstein, M.H. \& Helwig, E.B. (1970a). The cutaneous amyloidoses I. Localized forms. Archives of Dermatology, $102,8$.

Brownstein, M.H. \& Helwig, E.B. (1970b). The cutaneous amyloidoses II. Systemic forms. Archives of Dermatology, $102,20$.

Chow, C. \& Burns, R.E. (1967) Bullous amyloidosis. Archives of Dermatology, 95, 622.

GolTz, R.W. (1952) Systematized amyloidosis: A review of the skin and mucous membrane lesions and a report of two cases. Medicine, 31, 381.

HURLEY, H.J. \& WeINBERG, R. (1964) Induced intralesional haemorrhage in primary systemic amyloidosis. Archives of Dermatology, 89, 678.

KYLE, R.A., KotTKe, B.A. \& SChIRGER, A. (1966) Orthostatic hypotension as a clue to primary systemic amyloidosis. Circulation, 34, 883.

LEHNER, T. (1968) Oral biopsy in the diagnosis of amyloidosis. Israel Journal of Medical Sciences, 4, 1000.

LuBARSCH, O. (1929) Zur Kenntnis ungewohnlicher Amyloid ablagerungen. Virchows Archiv fur pathologische Anatomie und Physiolgie und fur klinische Medizin, 271, 867.

Moschcowitz, E. (1936) The clinical aspects of amyloidosis. Annals of Internal Medicine, 10, 73.

Muller, S.A., Sams, W.M. \& Dobson, R.L. (1969) Amyloidosis masquerading as epidermolysis bullosa acquisita. Archives of Dermatology, 99, 739.

Reimann, H.A., Sahyoun, P.F. \& Chaglassian, H.T. (1954) Primary amyloidosis. Archives of Internal Medicine, 93, 673.

Rukavina, J.G., Block, W.D., Jackson, C.E., Falls, H.F., Carey, J.H., Curtis, A.C., (1956) Primary systemic amyloidosis: a review and an experimental, genetic and clinical study of 29 cases with particular emphasis on the familial form. Medicine, 35, 239.

WARE, W.H. \& Silverman, S. (1961). Primary amyloidosis; review of the literature and report of a case. Journal of Oral Surgery, Anaesthesia and Hospital Dental Service, 19, 140. 